\title{
Lesbians, Gays, Bisexuals, and the Transgendered in Political Science: Report on a Discipline-Wide Survey
}

Julie Novkov, University at Albany, SUNY

Scott Barclay, University at Albany, SUNY

ABSTRACT This article reviews the results of a discipline-wide survey concerning lesbians, gays, bisexuals, and the transgendered in the discipline. We find that both research and teaching on LGBT topics have made some headway into the discipline, and that political scientists largely accept that LGBT issues can be fundamentally political and are worth studying and teaching for that reason. Nonetheless, troubling questions about discrimination both against those who conduct research concerning LBGT issues and LGBT individuals themselves remain.

"This campus is homophobic. A tenured faculty member warned me not to come out until I had tenure."

"Bending over for junk like LGBT studies will make Political Science more irrelevant than it already is."

"The most significant problem facing " $L B G T$ " political scientists is the manner in which their lifestyle and activism cloud and confuse their professional activities."

"LGBT is a nonissue and I like many others actively keep such garbage off the radar screen. It's a weak political agenda and does not merit any attention whatsoever."

"I don't think LGBT political scientists face any problems."

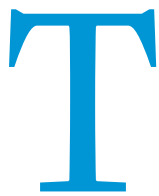

he Committee on the Status of Lesbians, Gays, Bisexuals, and the Transgendered in the Profession recently conducted a survey of the membership of the American Political Science Association (APSA). This survey, which asked a range of questions about the experiences of LGBT scholars, attitudes of other scholars toward LGBT scholars, and attitudes regarding research and teach-

Julie Novkov is a professor of political science and women's studies at the University at Albany, SUNY, where she also directs the graduate program in political science. She is a formerchair of APSA's Committee on the Status of Lesbians, Gays, Bisexuals, and the Transgendered in the Profession and currently serves as a member of the Executive Council. Scott Barclay is an associate professor of political science at the University at Albany, SUNY. His research in the last decade has focused on the political and social forces that shape the same-sex marriage discussion in the United States, with an emphasis on the factors that prompt different legislative and judicial responses from individual states. ing that incorporate LGBT topics, was the first full-scale study of opinions on these issues since 1993.

The survey results suggest that one's identity as a lesbian, gay man, bisexual, or transgendered person matters in the profession. Respondents, both those who identify as LGBT and those who do not, differed on how identity matters, with some arguing that it does not. But within the survey results lie debates over the extent and locations of discrimination based on identity and on the way that identity intersects with research. Further, respondents differed on how-and in a few cases whether-LGBT topics and issues should be incorporated into the research, teaching, and service missions of the discipline.

Respondents reported experiencing, witnessing, or participating in few acts of overt discrimination or active hostility toward LGBT individuals. Nonetheless, respondents did report specific instances, and identified, and in a few cases expressed, highly negative attitudes about LGBT political scientists and their place in the field, whether researching and teaching about LGBT issues or not. Given what we know about individuals' reluctance to express overtly discriminatory beliefs in surveys, we assume that what we report here does not encompass the full scope of hostility that LGBT individuals and those who research and teach on LGBT issues face.

Previous research on the experiences of political scientists of color and female political scientists has outlined the particular challenges they face, documenting a hostile climate in research and teaching (Alexander-Floyd 2008; Dion 2008; Sampaio 2006; Mathews and Andersen 2001; Breuning and Sanders 2007; Monforti and Michelson 2008).

Given this research, we expected to find that LGBT identity matters similarly for political scientists. Identity weaves through 
the experiences of acquiring a professional degree, getting a position and moving up the career ladder, and performing the basic triad of research, teaching, and service in faculty positions. But it also affects how we negotiate our collegial relations, and for many of us, how we think about the discipline and our place in it. This report answers some questions about how LGBT individuals negotiate their orientations and gender identities in the profession. It also raises important questions both for future research on this population and for individual political scientists themselves in how they think about the profession and their places in it.

\section{THE SURVEY}

The Web-based survey went into the field in the spring of 2007. It garnered 2,215 responses. Of these respondents, 1,883 (85\%) identified themselves as heterosexual, and $324(15 \%)$ identified themselves as LGBT. Of the LGBT respondents, 6 individuals (0.3\%) identified themselves as transgendered, $98(4.4 \%)$ as bisexual, 78 (3.2\%) as lesbians, and $142(6.4 \%)$ as gay men. The survey did not ask about transsexuality as an identity, but in the open-ended response opportunities, a few individuals identified themselves as transsexuals. With such a small response rate, we have concerns about the extent to which the respondents in fact represent the discipline as a whole. In particular, we do not know whether respondents were more likely to reply to the survey because of their strong opinions on LGBTs and LGBT issues. To understand more about the respondents, we can look at fuller demographic data for the profession and compare these data to ours; a full account of how the survey respondents compare to the broader discipline can be found in the appendix. The analysis to follow thus describes a population that is more female, less advanced in rank, and likely more youthful than the profession overall. We suspect that these response patterns may indicate a modest selection bias among respondents in favor of individuals who in the general population are more likely to be supportive of LGBT rights. Further, in most of the analysis, we do not distinguish between responses provided by graduate students and full professors, although there are clear power differentials based upon rank and status, with implications for the impact of individuals' attitudes on climate.

As table 1 demonstrates, all large fields had respondents who identified themselves as lesbians, gays, and bisexuals, with the largest percentages of LGBT respondents in political theory and public law, and the smallest in American politics and international relations. While the numbers are small enough to warrant caution, particularly interesting are the $7 \%$

Table 1 of political theory respondents who identified as lesbians and the $9 \%$ of public law respondents who identified as bisexual.

Table 2 shows the correlations between academic rank and orientation or identity for individuals who reported their ranks. ${ }^{1}$ As the numbers concerning age (and available in the appendix) suggest, individuals identifying as LGBT appear to be more prevalent in lower academic ranks and in contingent positions. Nonetheless, in apparent contrast to the pattern for women and people of color, the survey suggests no drop-off between the ranks of assistant and associate professor. Without a firm sense of LGBT representation in the discipline as a whole, it is difficult to say a lot about this information, but it does hint that younger and more junior cohorts are more likely to identify as LGBT (see table 3).

\section{IMPORTANT THEMES}

Despite our caveats about how well the respondents represent the discipline as a whole, we have drawn out some themes from the data that reflect areas for both optimism and concern. Some LGBT academics have significant anxieties about climate issues, and many respondents overall perceived some differences in the ways that LGBT academics negotiate their careers. While many respondents did not believe that one's LGBT status would have an overall negative impact upon career opportunities, advancement in the profession, collegial relations, or teaching, others reported detrimental experiences or troubling uncertainty.

A theme worth more exploration is how political scientists believe that our discipline should deal with sexuality as a factor in research and teaching about politics. Our respondents expressed strong and divergent opinions that intersected in interesting ways with debates over the centrality of positivism and the role of

\section{Respondents' Sexual Orientation and Gender}

\begin{tabular}{lllllll} 
& BISEXUAL & \multicolumn{1}{c}{ GAY } & LESBIAN & TRANS & HETERO & \multicolumn{1}{c}{ TOTAL } \\
\hline Female & 59 & 0 & 78 & 2 & 722 & $861(39.1 \%)$ \\
\hline Male & 39 & 142 & 0 & 3 & 1159 & $1343(60.1 \%)$ \\
\hline Total & $\mathbf{9 8 ( 4 . 4 \% )}$ & $\mathbf{1 4 2}(\mathbf{6 . 4 \% )}$ & $\mathbf{7 8 ( 3 . 2 \% )}$ & $\mathbf{6 ( . 3 \% )}$ & $\mathbf{1 1 8 3 ( \mathbf { 8 5 . 3 } \% )}$ & $\mathbf{2 2 0 4}$ \\
\hline
\end{tabular}

Note: The totals for transgendered and heterosexuals include three persons who did not identify as female or male.

Table 2

Area of Research Specialization and Orientation/Identity (Percentages in Parentheses)

\begin{tabular}{lccccccr} 
FIELD & BI & GAY & LESBIAN & TRANS & \%LGBT & HETERO & TOTALS \\
\hline American Politics & $26(3 \%)$ & $52(7 \%)$ & $22(3 \%)$ & $2(.3 \%)$ & $\mathbf{1 2 . 9}$ & $686(87 \%)$ & 788 \\
\hline Comparative Politics & $17(6 \%)$ & $18(6 \%)$ & $12(4 \%)$ & $0(0 \%)$ & $\mathbf{1 5 . 7}$ & $253(84 \%)$ & 300 \\
\hline International Relations & $13(3 \%)$ & $29(7 \%)$ & $16(4 \%)$ & $2(.4 \%)$ & $\mathbf{1 3 . 8}$ & $376(86 \%)$ & 436 \\
\hline Political Theory & $15(7 \%)$ & $13(6 \%)$ & $16(7 \%)$ & $0(0 \%)$ & $\mathbf{1 9 . 6}$ & $180(80 \%)$ & 224 \\
\hline Public Administration & $7(3 \%)$ & $19(9 \%)$ & $5(2 \%)$ & $1(.4 \%)$ & $\mathbf{1 5 . 3}$ & $177(85 \%)$ & 209 \\
\hline Public Law & $10(9 \%)$ & $6(5 \%)$ & $5(4 \%)$ & $1(.8 \%)$ & $\mathbf{1 9 . 3}$ & $92(81 \%)$ & 114 \\
\hline Other6 & $3(7 \%)$ & $2(4 \%)$ & $2(5 \%)$ & $0(0 \%)$ & $\mathbf{1 7 . 1}$ & $34(83 \%)$ & 41 \\
\hline Total & $\mathbf{9 1 ( 3 \% )}$ & $\mathbf{1 3 9 ( 9 )}$ & $\mathbf{7 8 ( 2 \% )}$ & $\mathbf{6 ( . 4 \% )}$ & $\mathbf{1 4 . 9}$ & $\mathbf{1 7 9 8 ( 8 4 \% )}$ & $\mathbf{2 1 1 2}$
\end{tabular}

Note: The percentages in this table do not match table 1 because some individuals declined to identify a field of expertise. 
Table 3

\section{Academic Rank}

\begin{tabular}{lccccccc} 
RANK & BISEXUAL & GAY & LESBIAN & TRANS & \%LGBT & HETERO & TOTAL \\
\hline Visiting/adjunct/instructor & $8(7 \%)$ & $8(7 \%)$ & $2(2 \%)$ & $1(1 \%)$ & $\mathbf{1 6 . 4}$ & $97(84 \%)$ & 116 \\
\hline Assistant professor & $24(5 \%)$ & $36(7 \%)$ & $15(3 \%)$ & $1(.2 \%)$ & $\mathbf{1 5 . 2}$ & $423(85 \%)$ & 499 \\
\hline Associate professor & $11(3 \%)$ & $25(7 \%)$ & $17(5 \%)$ & $0(0 \%)$ & $\mathbf{1 5 . 2}$ & $296(85 \%)$ & 349 \\
\hline Full professor & $18(4 \%)$ & $17(4 \%)$ & $11(3 \%)$ & $0(0 \%)$ & $\mathbf{1 1 . 0}$ & $372(89 \%)$ & 418 \\
\hline Dist/Emeritus/Admin & $0(0 \%)$ & $0(0 \%)$ & $0(0 \%)$ & $0(0 \%)$ & $\mathbf{0 . 0}$ & $39(100 \%)$ & 39 \\
\hline Other & $1(10 \%)$ & $0(0 \%)$ & $1(0 \%)$ & $0(0 \%)$ & $\mathbf{2 0 . 0}$ & $8(80 \%)$ & 10 \\
\hline Total & $\mathbf{6 2}$ & $\mathbf{8 6}$ & $\mathbf{4 6}$ & $\mathbf{2}$ & $\mathbf{1 3 . 7}$ & $\mathbf{1 2 3 5}$ & $\mathbf{1 4 3 1}$ \\
\hline
\end{tabular}

respondents) did not know if they had ever experienced discrimination (see table 4). This table reports responses to the question, asked only of selfidentified LGBT respondents, "Have you ever experienced discrimination as a political scientist because you were bisexual, transgendered, gay or lesbian?"

\section{LGBT Scholars Climbing the Career Ladder}

Table 5 displays responses to the question, "Have you ever experienced or witnessed a sit-

Table 4

\section{Discrimination}

\begin{tabular}{lc} 
RESPONSE & NUMBER RESPONDING \\
\hline Definitely yes & $37(13 \%)$ \\
\hline Probably yes & $34(12 \%)$ \\
\hline Probably no & $89(31 \%)$ \\
\hline Definitely no & $71(25 \%)$ \\
\hline Do not know & $56(20 \%)$ \\
\hline Total & $\mathbf{2 8 7 ( \mathbf { 1 0 0 } \% )}$ \\
\hline
\end{tabular}

theorizing in political science as a discipline. They also differed over whether studying LGBT issues was better pursued as a specific, concentrated research focus or as integrated elements within existing areas of research.

\section{Overview of Perceptions about Discrimination}

LGBT respondents were asked generally if they had ever experienced discrimination based on their sexual orientation or gender identity. Hearteningly, 160 respondents, or $56 \%$, responded that they definitely or probably had not. However, a quarter believed that they definitely or probably had, and an additional 20\% (56 uation in which you believe a person's perceived homosexuality, bisexuality, or transgendered identity predominantly helped, hurt or was deemed irrelevant in the following circumstances?" ${ }^{2}$ The survey asked about a broad range of potential circumstances; here we report the responses of particular interest.

While a few respondents identified issues as early as graduate school, over $90 \%$ either believed that LGBT identity was not relevant or did not know if it was; $3 \%$ of the respondents thought that LGBT identity helped in dissertation or thesis sponsorship and $4 \%$ thought it hurt. Nonetheless, a few respondents noted in open-ended questions that they had witnessed or experienced differential treatment, both negative and positive. For instance, one respondent explained, "One fellow graduate student left our department because they were discouraged from pursuing their research interests in this area for the listed reason. I tried to convince this student otherwise to no avail. I don't blame her for switching departments." Another, however, notes, "I was lucky enough to have historians, sociologists, and theorists who are out LGBT scholars mentoring me along the way" during graduate school.

The survey raises more cause for concern as LGBT individuals begin their job searches. While $9 \%$ of respondents (183) believed that LGBT identity had benefited them or someone else, $11 \%$ ( 226 respondents) reported that this identification had hurt. While $39 \%$ claimed that they had never seen a situation in which LGBT identity was relevant in a job search, $40 \%$ did not know for sure if LGBT identity had played a role in the searches they had witnessed or experienced (see table 5). A few respondents noted in open-ended answers that some Catholic or evangelical institutions have signaled their unwillingness to hire LGBT faculty members. One respondent noted hearing about controversy after starting work: "I've heard similar accounts from different sources that my own hiring (in my ostensibly liberal, open, welcoming dept.) for a tenure track position was negatively 
Table 6

Being Out
PEOPLE TO WHOM YOU ARE OUT

Only to LGBT individuals

Most/all colleagues

Some colleagues

Senior administration
NUMBER OF RESPONSES

$38(14 \%)$

$161(61 \%)$

$86(33 \%)$

$62(24 \%)$ influenced by my sexual orientation; in the end I did get the job because the first two candidates declined the position." Another reported frankly, "I have never witnessed any of these things, but I do believe that it would be reasonable to consider a person's homosexual conduct or lifestyle (negatively) in hiring." Some respondents insisted that sexual orientation and gender identity are largely irrelevant to professional opportunities and advancement: "I don't think there are significant problems for LGBT political scientists. I have never heard of decisions being influenced because of sexual orientation." Others, however, claimed that LGBT status carries some cachet for some departments and universities.

Of the respondents, 139 (7\%) claimed that they had witnessed or experienced an instance in which a person's perceived LGBT sexual orientation or identity had negatively affected that person's reappointment, tenuring, or promotion; $4 \%$ believed that orientation or identity had helped someone. While $43 \%$ claimed that orientation and identity had always been irrelevant factors in the personnel decisions they had witnessed or experienced, $46 \%$, or 914 respondents, did not know for sure whether identity or orientation had ever played a role in an institution's choice to reappoint, tenure, or promote a faculty member (see table 5 ).

A heartening number of LGBT-identifying respondents (179, or $62 \%$ ) reported that they did not believe their jobs would be endangered if their supervisors or chairs knew their identification as lesbian, gay, bisexual, or transgendered. However, 8\% (23 respondents) believed that their jobs would be in danger. Many respondents expressed uncertainty though -69 individuals (24\%) felt that they were probably not at risk but could not say they were definitely safe, and an additional 6\% did not know (see table 5).

\section{Being Out in the Workplace}

Related to this question, the survey asked LGBT individuals about the extent to which they are out in professional settings, asking respondents to check all categories that applied. Table 6 shows the responses. More than $60 \%$ of LGBT respondents reported being out in their professional lives. ${ }^{3}$ One-third, however, were out only to some colleagues, and less than a quarter were out to senior administrators. Respondents reported different ways of being out, ranging from bringing same-sex partners to events to actively identifying themselves at their institutions as LGBT. One respondent, for instance, explained, "I was an out lesbian in my department with LGBT information posted on my office door (which apparently did cause some behind the scenes stir, I'm told)." Several bisexuals reported that being out was more complex for them: bisexual individuals in long-term monogamous relationships with members of the opposite sex are presumed to be straight. As one respondent noted, "I am bisexual but married to a person of the opposite sex, so many people assume I am straight."

A few respondents pointed out that their identities as transgendered or transsexual also complicated the question of being out. One explained, "I am a female to male transgender person. That is not my sexual orientation, that is my gender/gender identity. I identify as male (that is how I am viewed in all circumstances). However, I also am gay, as in I have a male partner." Unfortunately, the survey did not separate gender identity carefully enough from sexual orientation, so we cannot draw conclusions about how gender identity and sexual orientation function as a dynamic for transgendered or transsexual individuals who may identify as lesbians, gay men, bisexuals, or straights.

\section{Collegiality and Benefits}

Collegial relations are an important, if intangible, part of academic life. These encounters range from formal service together on committees and other departmental interactions and in the classroom to the informal social relationships that develop in many academic units among peers. Less than half of respondents, $42 \%$ (821 individuals), believed that academics' identification as LGB and/or $\mathrm{T}$ was irrelevant to how they interacted with their colleagues. An additional 88 respondents (4\%) felt that LGBTs' collegial relations were better because of their status or identity. However, 16\% (324 individuals) reported that they had experienced or witnessed worse collegial relations for LGBT individuals than for non-LGBT individuals, and an additional $37 \%$ reported uncertainty.

Informal collegial interactions often involve spouses, partners, and families. Sometimes these interactions go well for individuals with same-sex partners. One respondent wrote, "I had a partner (12 yrs)-she (and the information) was well received and with respect by faculty, students, colleagues. Having a partner actually makes it easier to be out, because spouses/partners come up in conversation. When I would mention my partner, sometimes students secretly came out to me." Other respondents, however, reported that some colleagues do not treat their relationships as on par with relationships between opposite-sex couples. As one respondent explained, "Some colleagues treat us exactly like other 'married' (straight) people; others clearly think our relationship is something 'less than' their straight relationships." Another noted that, while many colleagues were comfortable with the partnership, "Even 'tolerant' and non-homophobic colleagues, however, seem not to recognize the kinds of assumptions embedded in their assumptions about things like marriage (for example, that marriage signals real commitment, that kids are 'better off' with married parents, etc)." Assumptions equating marriage with real commitment can have real consequences: "Informally, they try to be egalitarian. Formally and institutionally, they offer spousal hires to far more junior colleagues but not to my partner."

The area in which the largest number of respondents saw negative effects was (unsurprisingly) in the benefits universities provide or subsidize. Although the survey was conducted before the disciplinary controversy over siting the APSA annual meeting in New Orleans, where Louisiana's anti-same-sex marriage constitutional amendment denies state officials the authority to recognize committed same-sex partners in any way, this issue clearly resonated with respondents: $18 \%$ (346 respondents) reported experiencing or witnessing situations in which an individual's identification as LGB or T negatively affected that person's access to 


\section{Table 7}

\section{Benefits and Career Decisions}

\begin{tabular}{lcc} 
& $\begin{array}{c}\text { LACK OF BENEFITS } \\
\text { INFLUENCED DECISION }\end{array}$ & $\begin{array}{c}\text { AVAILABILITY OF BENEFITS } \\
\text { INFLUENCED DECISION }\end{array}$ \\
\hline Yes & $229(12 \%)$ & $277(14 \%)$ \\
\hline No & $1,683(88 \%)$ & $1,637(86 \%)$ \\
\hline Total & $\mathbf{1 , 9 1 2}$ & $\mathbf{1 , 9 1 4}$ \\
\hline
\end{tabular}

benefits, $4 \%$ ( 73 respondents) reported positive effects, and $38 \%$ saw status and gender identity as irrelevant. When asked about the most important issue facing LGBT members of the profession, $13.6 \%$ of the 876 respondents specifically criticized the lack of benefits for same-sex partners. In two other questions, 229 individuals asserted that a lack of domestic-partner benefits had influenced their decisions about positions, and 277 respondents reported taking the availability of benefits into account in making decisions about positions (see table 7).

\section{LGBT Issues and LGBT Scholars in the Classroom}

Identity issues present themselves in complex and interesting ways in the college classroom. On one level, we can consider the identity of the instructor and how students interpret that identity. Sexual orientation and gender identity are not identical to other identity issues, due to the greater opportunities for conscious or unconscious "passing." To what extent do students perceive their instructors to be lesbians, gay men, bisexuals, transgendered, and/or transsexual? Queer sexual orientations and gender identities may not be as visible to students as non-white racial status or femininity. The survey addressed instructors' beliefs about how their students perceive them, asking, "if you teach, whether you are straight or LGBT, do you believe that your students think they know your sexual orientation?" 4 (see table 8 ). While $21 \%$ did not know what their students thought about their sexual orientations, $66 \%$ believed that their students either knew from their signals or assumed that their instructors were straight or lesbian, gay, or bisexual. Only $7 \%$ of the respondents believed that their students did not peg them as either straight or LGB, either because the instructors were intentionally ambiguous or because they believed that students do not make assumptions. ${ }^{5}$

In addition to making assumptions or reading cues delivered by their instructors, students apparently sometimes signal their own orientations and identities to their instructors. Eighty respondents (4\%) said that students were out in all of their classes, and overall nearly $60 \%$ reported that students were out to them in at least some of their classes. Additionally, 22\% said that students were not out to them and $19 \%$ claimed uncertainty. LGBT instructors reported more awareness of their students' orientations and gender identities than their straight colleagues. They also were more likely to report that students came out in each category. Still,

Table 9 Students Out Themselves
Table 8

\section{Students Out Instructors}

\begin{tabular}{lc} 
DO STUDENTS THINK THEY KNOW? & NUMBER OF RESPONSES \\
\hline Yes (I give clear cues) & $538(28 \%)$ \\
\hline Yes (the students make assumptions) & $699(37 \%)$ \\
\hline No (I am purposely ambiguous) & $103(5 \%)$ \\
\hline No (students do not make assumptions) & $45(2 \%)$ \\
\hline Don't know & $392(21 \%)$ \\
\hline Other, please specify & $115(6 \%)$ \\
\hline Total & $\mathbf{1 8 9 2 ( \mathbf { 1 0 0 } \% )}$ \\
\hline
\end{tabular}

more than half of straight instructors had out students in some of their classes. Further, the percentages of LGBT and straight instructors who reported not having any students reveal their orientations were relatively close $(19.2 \%$ for LGBT instructors and $22.7 \%$ for straight instructors) (see table 9).

These issues raise related questions about the incorporation of LGBT topics in political science classes. To what extent are LGBT issues taught in political science classes, and when do political scientists think it is necessary or appropriate to do so?

Among the respondents, those who identified as LGBT were more likely to incorporate LGBT issues or topics in their teaching, with more than half doing so on occasion and less than a quarter reporting never addressing any LGBT issues. But many straights also incorporated LGBT content in their classes. Nearly $60 \%$ reported teaching LGBT issues and topics at least occasionally (see table 10).

At what level are LGBT issues or topics incorporated in political science classes? The survey asked about incorporating LGBT issues into research and teaching in political science (research is discussed below). The question respondents answered was, "What is your assessment of how appropriate the following are in political science?" Respondents rated a variety of teaching scenarios and research generally as very appropriate, appropriate, not appropriate, or not familiar. While between $10 \%$ and $12 \%$ of respondents were uncertain about the appropriateness because of their unfamiliarity with LGBT politics, respondents overwhelmingly believed that the incorporation of LGBT politics in research and teaching was appropriate or very appropriate. The strongest resistance was to entire undergraduate courses focusing on LGBT

\begin{tabular}{lccccccc} 
& BISEXUAL & GAY & LESBIAN & TRANS & \%LGBT & HETERO & TOTAL \\
\hline Do not know & $11(13 \%)$ & $13(11 \%)$ & $6(9 \%)$ & $1(25 \%)$ & $\mathbf{1 1 . 2}$ & $321(21 \%)$ & $352(19 \%)$ \\
\hline No & $20(24 \%)$ & $23(19 \%)$ & $10(15 \%)$ & $0(0 \%)$ & $\mathbf{1 9 . 2}$ & $350(23 \%)$ & $403(22 \%)$ \\
\hline Yes, in all classes & $9(11 \%)$ & $7(6 \%)$ & $4(6 \%)$ & $0(0 \%)$ & $\mathbf{7 . 2}$ & $60(4 \%)$ & $80(4 \%)$ \\
\hline Yes, in most classes & $8(10 \%)$ & $22(18 \%)$ & $12(18 \%)$ & $0(0 \%)$ & $\mathbf{1 5 . 2}$ & $205(13 \%)$ & $247(14 \%)$ \\
\hline Yes, in some classes & $34(41 \%)$ & $57(47 \%)$ & $36(53 \%)$ & $3(75 \%)$ & $\mathbf{4 7 . 1}$ & $605(39 \%)$ & $735(40 \%)$ \\
\hline TOTAL & $\mathbf{8 2}$ & $\mathbf{1 2 2}$ & $\mathbf{6 8}$ & $\mathbf{4}$ & & $\mathbf{1 , 5 4 1}$ & $\mathbf{1 , 8 1 7}$ \\
\hline
\end{tabular}


Table 10

Teaching LGBT Issues and Topics

\begin{tabular}{lccccccr} 
& BISEXUAL & GAY & LESBIAN & TRANS & \%LGBT & HETERO & TOTAL \\
\hline Regularly & $20(23 \%)$ & $33(27 \%)$ & $5(10 \%)$ & $2(40 \%)$ & $\mathbf{2 2 . 5}$ & $182(11.6 \%)$ & $\mathbf{2 4 2}$ \\
\hline On occasion & $47(54 \%)$ & $63(51 \%)$ & $35(69 \%)$ & $0(0 \%)$ & $\mathbf{5 4 . 3}$ & $742(47.3 \%)$ & $\mathbf{8 8 7}$ \\
\hline No & $20(23 \%)$ & $28(23 \%)$ & $11(22 \%)$ & $3(60 \%)$ & $\mathbf{2 3 . 2}$ & $645(41.1 \%)$ & $\mathbf{7 0 7}$ \\
\hline Not applicable & 8 & 14 & 3 & 1 & & 249 & $\mathbf{2 7 5}$ \\
\hline Total (excluding NA) & 87 & 124 & 51 & 5 & & 1,569 & $\mathbf{1 , 8 3 6}$ \\
\hline
\end{tabular}

resistance to LGBT research overall, with only $11 \%$, or 254 respondents, claiming that LGBT research was inappropriate in their fields (an additional 262 respondents answered that they did not know if LGBT research was appropriate). In terms of the advice that scholars have received, few respondents reported either being discouraged from working on LGBT topics or encouraged to

politics, but even here, almost three-quarters of the respondents believed that such courses were appropriate or very appropriate (see table 11).

In discussing teaching, survey respondents made conflicting remarks. As Anna Sampaio has noted, issues of identity in the classroom become more complex when an instructor with a subordinated identity is teaching the critical politics of that identity (Sampaio 2006). One respondent identified student prejudice as the most significant problem for LGBT members of the academy. After describing working at an institution with a welcoming and comfortable climate, the respondent continued, "problems of discrimination tend to occur with undergraduate students who are uncomfortable with professors and teaching assistants who are openly homosexual or transsexual, which negatively affects their careers through student evaluations and inhibiting the ability of the professor to have the necessary respect to effectively teach."

However, other respondents saw similar interactions-students reacting negatively to their instructors' orientations or identities and challenging their instructors' pedagogical treatments of LGBT topics-but read the students' complaints as legitimate. One respondent explained, "I heard from students that they found it very annoying that their professor in another class spent so much time talking about her own issues related to her lesbian identity. I expect that such discussions hurt her teaching evaluations, but, of course, I have no direct evidence of such." More information about how attitudes break down by field can be found in the appendix.

\section{LGBT Research}

We also consider LGBT research and how members of the profession view it. The survey asked respondents, regardless of their gender identity or sexual orientation, "Have you ever been discouraged from conducting research on LGBT topics?" The survey also asked, "Have you ever been encouraged to conduct research on LGBT topics?" As noted in table 11, few respondents expressed work on such topics, though more than twice as many respondents reported encouragement (see table 12).

Aside from encouragement or discouragement, LGBT issues are undeniably a part of the discipline. The survey asked if respondents' research interests include LGBT topics. While overall 63\% reported not engaging LBGT topics in their research, $15 \%$ did so extensively or somewhat, and an additional $22 \%$ reported doing so a little. As table 13 indicates, sexual orientation and gender identity were factors here, with LGBT individuals reporting themselves as engaging in extensively or somewhat in research on LGBT topics at higher rates.

While choices of research topics are highly individual, at least a few respondents reported having shied away from LGBT topics for fear of discrimination either against their scholarly work or against them if they were identified as LGBT. One respondent explained, “There are many reasons I haven't pursued research on LBGT issues, but I do believe that if I were to do so, it would be perceived as a niche topic, and people would suspect I was gay or bisexual." However, another respondent notes that, while he recognizes the possibility of being identified as gay, he does not allow this to alter research trajectories: "I also worry, frankly, sometimes when I am introduced as someone who has published on gay rights (as happens with a consulting job every couple months) that listeners will make that assumption. But I just put the worry aside, it is not a big deal, it is a thought that crosses my mind, and I'm surprised it still crosses."

In considering acceptance of LGBT research, some patterns emerge when other factors are considered. Figure 1 sorts responses by faculty rank. The graph illustrates the percentages of nontenure-track faculty members, assistants, associates, fulls, emeriti, distinguished professors, and top administrators who see research on LGBT topics as highly appropriate, appropriate, and not appropriate in their fields (as well as those reporting that they are unfamiliar with such research). As the survey did not define "appropriate," respondents likely had a range of interpretations

Table 11

\section{LGBT Topics in Research and Teaching}

ITEM

Research on topics of LGBT

Gesearch on topics of LGBT

Undergraduate courses on LGBT politics

Integrating topics on LGBT politics into undergraduate courses
VERY APPROPRIATE

$915(41 \%)$

717 (33\%)

$722(33 \%)$

$902(41 \%)$
APPROPRIATE

$778(35 \%)$

NOT APPROPRIATE

NOT FAMILIAR

$882(40 \%) \quad 348(16 \%) \quad 254(12 \%)$

$847(39 \%)$

$385(18 \%)$

$244(11 \%)$

$828(38 \%) \quad 257(12 \%)$

$213(10 \%)$ 
Table 12

\section{Discouragement and Encouragement}

REPORTED DISCOURAGEMENT REPORTED ENCOURAGEMENT

\begin{tabular}{lcc}
\hline Yes & $104(5 \%)$ & $227(11 \%)$ \\
\hline No & $2,036(95 \%)$ & $1,910(89 \%)$ \\
\hline
\end{tabular}

in mind as they answered the question. Enthusiasm for LGBT research appears to peak among associate professors, with half of them rating it as very appropriate and an additional $30 \%$ seeing it as appropriate. Interestingly, assistant professors were more likely than either associates or fulls to classify LGBT research as inappropriate in their fields.

Less surprising is the relationship between attitudes about the acceptability of LGBT research and the subfield of the respondent. Figure 2 illustrates the responses by primary subfield. Respondents in the fields of public law, American politics, and political theory were the most enthusiastic, with respondents from international relations expressing the strongest opposition and the greatest lack of familiarity.

\section{Most Significant Issues}

The survey encouraged respondents, regardless of their orientations or gender identities, to reflect on the challenges for LGBT individuals in the pro-
Figure 1

\section{Rank and Attitudes about LGBT Research}

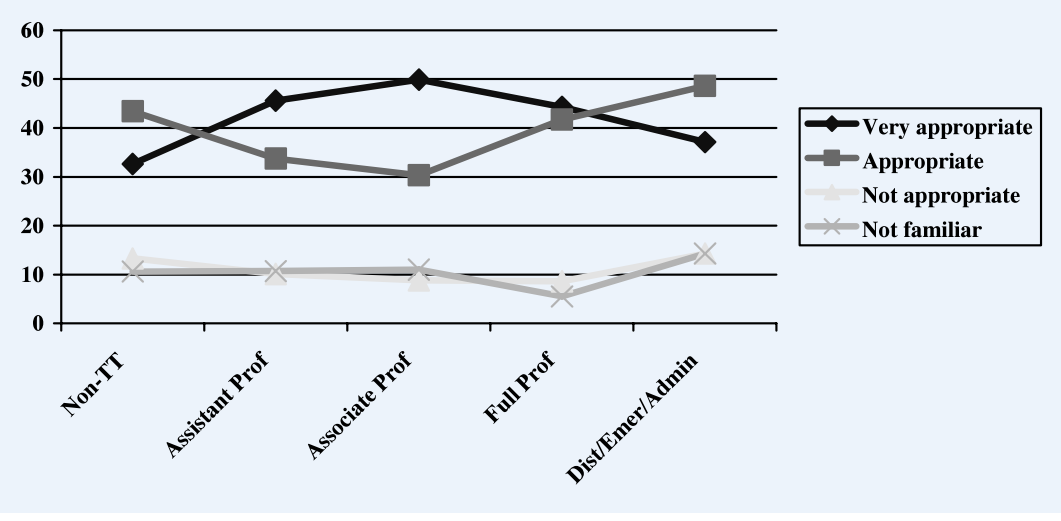

Figure 2

\section{Subfield and Attitudes about LGBT Research}

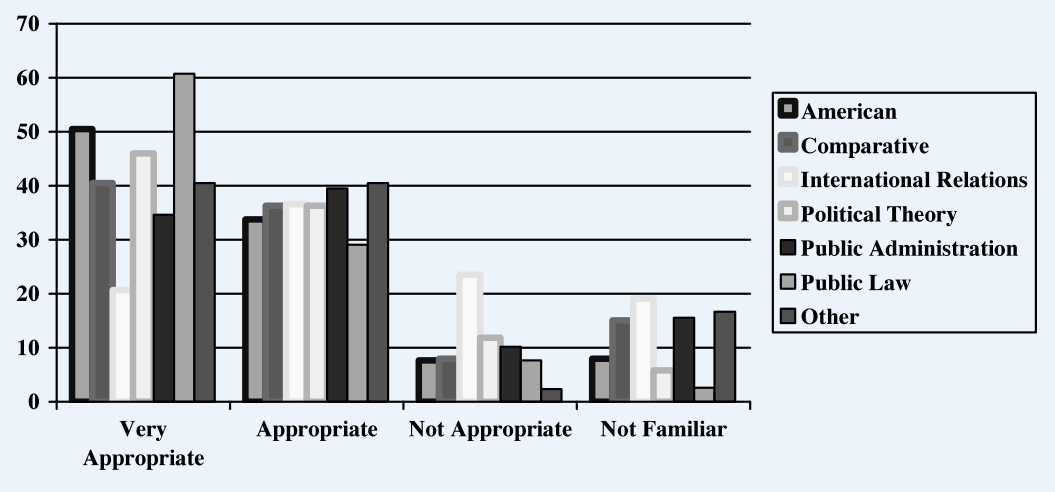

fession. Specifically, respondents were asked, "What do you see as the most significant problems confronting LGBT political scientists now? What kinds of changes in policies, practices, etc. would make life better for LGBT political scientists on your campus or in your organization? In the profession?" The questions produced 874 comments that covered a wide range of issues and concerns. The largest group of respondents identified general prejudice or homophobia in society as the most significant problem. Many of these respondents expressed a belief that the academy was generally less of a problem than the broader social context outside of the universities' doors. As one respondent explained, "I suspect social changes are a lot more important than anything that might change in the discipline." Related to these kinds of ideas were those expressed by the additional $3.2 \%$ of respondents who highlighted discriminatory state or national policies. Some of these respondents framed the university as a haven: "The political environment beyond campus always creates pressure and potential unhappiness and discrimination. On campus life is 'relatively' good."

As table 14 indicates, however, some respondents did identify specific problems on campus. Many-13.6\% of those who answered-believed that lack of benefits for same-sex partners was the most significant issue. Another $2.4 \%$ identified students' negative attitudes toward LGBTs as the biggest problem. Twelve respondents (1.4\%) wrote about religious discrimination or bigotry at Christian institutions, some noting particular problems at Catholic schools. As one respondent explained, "I teach at a conservative 
Table 14

\section{Most Significant Problems}

\begin{tabular}{lc}
\hline BIGGEST ISSUES & RESPONDENTS \\
\hline Generalized prejudice/homophobia & $196(22.4 \%)$ \\
\hline Lack of partner benefits & $120(13.6 \%)$ \\
\hline $\begin{array}{l}\text { Lack of acceptability of LGBT research as “political } \\
\text { science" }\end{array}$ & $114(13 \%)$ \\
\hline I don't know & $85(9.7 \%)$ \\
\hline No discrimination exists & $78(8.9 \%)$ \\
\hline $\begin{array}{l}\text { Need to mainstream LGBT research/not pursue } \\
\text { it as an isolated phenomenon }\end{array}$ & $68(7.8 \%)$ \\
\hline $\begin{array}{l}\text { Active hostility toward LGBT research as too } \\
\text { "personal” or too "political” }\end{array}$ & $36(4.1 \%)$ \\
\hline Lack of visibility of LGBT scholars & $33(3.8 \%)$ \\
\hline \begin{tabular}{l} 
Hostile state/national policies or politics \\
\hline Discrimination by students
\end{tabular} & $28(3.2 \%)$ \\
\hline $\begin{array}{l}\text { Respondent expressed hostility toward LGBTs } \\
\text { themselves }\end{array}$ & $21(2.4 \%)$ \\
\hline Religious prejudice or homophobia in the workplace & $12(1.4 \%)$ \\
\hline $\begin{array}{l}\text { Respondent advocated cultivating blindness toward } \\
\text { sexual orientation }\end{array}$ & $10(1.1 \%)$ \\
\hline \begin{tabular}{l} 
Other \\
\hline
\end{tabular} & $54(6.2 \%)$ \\
\hline
\end{tabular}

Catholic college where 'out' LGBT professors are not tolerated by the administration."

Other respondents raised issues about the profession more broadly $-13 \%$ were concerned that LGBT politics is not fully accepted as legitimate political science. As one respondent wrote, "I think that, in terms of epistemology, dominant research areas and disciplinary culture political science is still oriented primarily around the experience of white, heterosexual males." An additional $7.8 \%$ argued for the mainstreaming of research on LGBT issues and warned against ghettoization of LGBT research (we will discuss this further below). Another $3.8 \%$ claimed that the lack of visibility of LGBT scholars was the most significant problem.

Some respondents had more confrontational ideas-78 (8.9\%) insisted that no discrimination exists. One respondent wrote, "LGBT people do not have any problems that are related to their sexual orientation or sexual identity in our organization. And no, there are no hidden barriers either." Another 4.1\% expressed hostility toward LGBT research. One type of objection was that this research is insufficiently objective, exemplified by the respondent who wrote, "It is a problem for anyone to confuse his/her personal and professional lives. This seems to be more common with LGBT academics than others." Another accused LGBT scholars of engaging in "voluntary marginalization through [their] identity politics agenda." Twenty respondents, comprising $2.3 \%$ of those who answered, objected to LGBT individuals themselves: "The most significant problem facing LGBT political scientists is their self-understand [ing] of themselves in terms of their sexual orientation and their pursuit of a lifestyle that is harmful to them and society."

Ten respondents advocated cultivating conscious ignorance of orientation and gender identity, akin to colorblindness with respect to race. As one respondent wrote, "Why should it matter if someone is straight or gay from the vantage point of a political scientist? We should step away from this and move on toward more necessary issues." Another simply asserted, "Sexuality should not be relevant in the workplace."

Finally, some responses could not be categorized, and 9.7\% of the respondents specifically wrote that they did not know the most significant problem facing LGBTs in the profession.

Overall, these responses raise an interesting tension among respondents over how to incorporate LGBT issues into the profession. Some insisted that LGBT issues have to be integrated into and interrogated through mainstream political science questions and approaches. One respondent explained, "like research on any topic, research on LBGT topics are 'serious political science' as long as such work is rooted in general political science questions." The respondent went on to encourage more focus on "questions about social mobilization, the use of issues in campaigns, the politics of stigmatized groups, etc." However, the respondent continued, "I do not believe that courses devoted to understanding 'what it's like to be LGBT' are legitimate political science (any more than courses devoted to understanding 'what it's like to be' British, or female, or white, or Asian or whatever are legitimate political science)." Respondents who took this approach encouraged more attention to LGBT issues in political science, but advocated against incorporating LGBT issues into the discipline through non-positivist or theoretical investigations. Some respondents also expressed concerns about creating specific intellectual spaces for studying LGBT issues in isolation. One such respondent advocated for "resisting the urge to hibernate in an APSA section-it's too easy to stay in the ghetto and not have much of an influence on the discipline that way. I've seen and fought that in my own primary section."

Another group of respondents, however, saw the study of LGBT issues as a site for expanding the boundaries of the discipline both in terms of substance and in terms of acceptable epistemologies. One respondent, who critically noted "disciplinary biases towards positive empiricism and the parochial views of the discipline's membership," argued for thinking through basic disciplinary boundaries more critically by engaging LGBT issues. This respondent explained, "I believe that what gets defined as 'the political,' while variable across faculty and the subfields, is rather narrow and thus constrains the definition of 'serious political science." Another respondent mused, "Perhaps because LGBT topics often are interdisciplinary in nature (gender theory as well as 'normal' political science), they are not as easily accessible to other political scientists." The implication of this for this group of scholars, however, is that political science should expand to incorporate these issues and the epistemological approaches that can grapple effectively with them.

This disagreement picks up on crosscutting tensions in the discipline over the relationship between politics and science and over the scope and breadth of epistemologies that belong in political science. A handful of respondents, as noted above, vocally objected to LGBT research generally as inappropriate. Some of these respondents seemed to be motivated by simple animus toward LGBTs, as described above. But others saw research on LGBT issues when performed by LGBT scholars as crossing the firm line that they endorsed between science and advocacy. Several respondents expressed this concern in almost the same words. One wrote, "I do not think that most of the work being done on 
this issue is serious political science. Instead, I think it is an aggressive advocacy effort." In these comments, respondents almost uniformly distinguished between "science" and "advocacy," implying or stating that advocacy does not constitute legitimate political science and in fact runs counter to the discipline's core missions.

Other respondents who criticized LGBT research did so more on methodological and epistemological grounds. Probably the most pointed comment of this nature came from the respondent who wrote, "Frankly, I think this work borders on academic fraud. It is better situated in a critical theory department or the like. (BTW, I think political theory should be shuffled off that way too.)" A less hostile respondent wrote, "LGBT political scientists need to be able to self-identify as such even if they do not necessarily deal primarily with LGBT topics in their research. LGBT research, in turn, should not be so dominated by people with postmodern/queer activist orientations. Let's get out of the ghetto, folks!" The sense of these statements and others like them is that LGBT research in political science is insufficiently positive and empirical and rests too much on cultural studies and theory. These respondents did not by and large appear to object to the study of LGBT topics as political science. In fact, some actively advocated for more research on LGBT topics. But they wanted the research to fit within particular disciplinary frameworks, to the point that they argued implicitly that the epistemological and methodological underpinnings of much work on LGBT topics was the key factor in de-legitimating the research, far above and beyond its substantive focus.

\section{CONCLUSION: WHAT DO WE NEED TO KNOW?}

\section{AND WHERE DO WE GO FROM HERE?}

Overall, the survey presents a mixed picture for LGBT members of the profession. As noted at the outset, we cannot be sure that the survey accurately represents the levels of acceptance of, toleration for, and discrimination against LGBT political scientists. The results suggest, however, that both research and teaching on LGBT topics have made some headway into the discipline, and that political scientists largely accept that LGBT issues can be fundamentally political and are worth studying and teaching for that reason. Nonetheless, troubling questions about discrimination both against those who conduct research concerning LBGT issues and LGBT individuals themselves remain.

One important implication of the survey is that overall the academy should be collecting more data on sexual orientation and gender identity. We believe that questions concerning orientation and identity should be added to the National Survey of Earned Doctorates and other large-scale projects that regularly collect data on political scientists and academics in other disciplines.

Another issue that should be studied further is how LGBT individuals experience different types of institutions. The survey results highlight particular issues with religious institutions, a topic worthy of more in-depth investigation. In addition, we note that several states in the United States now have specific constitutional language barring any recognition of the incidents of marriage for same-sex couples, which has been used to strip benefits from the same-sex partners of political scientists employed by state universities. We do not know enough about the range of benefits offered by state institutions, and how this range compares to the range offered by private institutions.

The survey also raises questions about how these issues play out for political scientists who live and work in other nations.
Only $10 \%$ of the respondents were not living in the United States, but some of these respondents noted that their concerns and issues reflect the different cultural, political, and social configurations of LGBT issues in their national and local contexts. As one respondent pointed out, "In Sweden it is much more accepted to be gay or lesbian than in the rest of the world. I have a hard time believing that one's sexual preference would be a problem in the ways you asked." Another respondent criticized the survey from the opposite perspective, claiming that "US academia is already an island of tolerance for LGBTs" in comparison to other nations. This respondent urged the LGBT status committee to attend more to the circumstances of LGBTs in nations and regions where hostility and prejudice have far worse real-world consequences: "this committee [should] team up with Campaign for HR etc. to bring LGBT's outside this island of tolerance ... If you could do that ... I think it would be world-changing not only for the persecuted scholars but for the many in the US who have no idea that realworld persecution of LGBT's goes beyond the sorts of things mentioned in this survey-e.g., have you ever been thrown in jail on the basis of your LGBT status, etc."

The survey did not deal with the differences between sexual orientation and gender identity, and only six respondents identified themselves as transgendered. The profession is just beginning to grapple with the distinct issues that transgendered and transsexual political scientists face, and these issues often receive short shrift in broader discussions about LGBT concerns. For instance, in the recent highly charged debate over holding APSA's annual meeting in New Orleans and potential discrimination against members of the profession in particular locations, few people discussed the significance of the presence or absence of city codes prohibiting discrimination based on gender identity in the locations where profession-wide meetings are held. Several respondents expressed frustration about ignorance regarding identity issues both in the survey and more broadly in the profession. One respondent summed up the problem, stating, "I also think ... that discrimination against transgendered people is by far the most unaddressed of the LGBT problems that most campuses and organizations should be tackling."

The kinds of issues raised about gender identity varied. Many respondents noted the lack of visibility and the conflation of orientation and gender identity. Some noted that transsexuals who exhibitfixed gendered identities may face less discrimination if their transsexuality is not widely known. One respondent explained, "There is no discrimination that I can discern against me as a transsexual woman, but the lack of any LGBT perspectives in any of our seminars is noteworthy. It's as if no one has even thought of it." Another wrote, "Being transgendered is both more and less difficult than being gay because I in my mind I am a girl but in my body I am a guy. I am probably too old to change at this point, so it will remain a fantasy. People do not understand the difference between sexual identity and sexual orientation." Still another witnessed that transgender students are invisible on campus, though institutional actors have been trying to determine whether the campus climate is hospitable to them. However, for transgender individuals, basic accommodations that everyone else takes for granted can be highly problematic: "A transgender colleague has not been able to use a bathroom on campus." Further, individuals' own definitions of their gender identities are sometimes not respected; as a respondent explained, "our colleagues refuse to change the pronoun they use, even 3 years after the transition." 
Overall, though, the survey results support the idea that LGBT issues and queers themselves are an inextricable part of the discipline. Considering queer identities and issues can greatly inform how we think about politics, how we think about political science, and how we think about the meaning of identity as professionals. As one respondent, in commenting on the dilemmas of differential treatment, remarked:

Bring 'em on! I believe acknowledging who we "know" ourselves to be the first step towards a hope of comprehending also how that position affects our ability to "know" and authority to speak "truth." My only demand of those who would label me as gay or queer is that they take account of their own identities and ideologies and acknowledge these "labels" as grants of more or less authority to relative to my own (in) ability to speak intelligibly.

\section{NOTES}

We thank the Committee on the Status of Lesbians, Gays, Bisexuals, and the Transgendered in the Profession for developing the survey; Bahram Rajaee and Sean Twombly from APSA for their assistance in administering the survey and providing comparative data on the APSA membership; Adam Kress for his assistance in formatting the raw data; Ken Sherrill and Susan Burgess for their input; and Joel Bloom for his helpful comments and suggestions throughout.

1. The drop in the number of respondents for this question is likely attributable to non-responses from graduate student members of APSA. We note that the percentage of respondents to the rank question who reported being LGBT is lower than the percentages of LGBT respondents for other questions, perhaps suggesting that more graduate students identify as LGBT than other cohorts of APSA members.

2. As the discussion in the article explains, many respondents expressed frustration with the framing of the question, as they reported having observed or experienced situations in which a person's sexual orientation or identity both helped and hurt.

3. Interestingly, this number exceeded the number of LGBT respondents who reported being out "to everyone" in non-professional settings (154 individuals, comprising $53 \%$ of the respondents to this question). Nineteen individuals, or
$7 \%$ of the total, answered that they were out to no one in non-professional settings.

4. This question is an example of an implicit rendering of transgender identity as an orientation. A handful of respondents noted this problem, pointing out that gender identity and sexual orientation are distinct concepts.

5. Of the $6 \%$ responding "other," several mentioned having a spouse or partner in the same department or at the university, and others explained that they mention their partners or spouses on social networking sites. A few stated that they come out in some classes but not others.

6. This category includes all fields that totaled fewer than 100 respondents. Among the fields mentioned were political behavior, political communication, methodology, political sociology, political economy, women's studies, and professional politics.

\section{REFERENCES}

Alexander-Floyd, Nikol. 20o8. "'Written, Published ... Cross-Indexed, and Footnoted': Producing Black Female Ph.D.s and Black Women's and Gender Studies Scholarship in Political Science." PS: Political Science and Politics 41 (4): 819-29.

Breuning, Marijke, and Kathryn Sanders. 2007. "Gender and Journal Authorship in Eight Prestigious Political Science Journals." PS: Political Science and Politics $40(2): 347-51$.

Dion, Michelle. 2008. "All-Knowing or All-Nurturing? Student Expectations, Gender Roles, and Practical Suggestions for Women in the Classroom." PS: Political Science and Politics 41 (4): 853-56.

Mathews, A. Lanathea, and Kristi Andersen. 2001. "A Gender Gap in Publishing? Women's Representation in Edited Political Science Books." PS: Political Science and Politics 34 (1): 143-47.

Monforti, Jessica Lavariega, and Melissa Michelson. 2008. "Diagnosing the Leaky Pipeline: Continuing Barriers to the Retention of Latinas and Latinos in Political Science." PS: Political Science and Politics 41 (1): 161-66.

Sampaio, Anna. 2006. "Women of Color Teaching Political Science: Examining the Intersections of Race, Gender, and Course Material in the Classroom." PS: Political Science and Politics 39 (4): 917-22.

Sedowski, Leanne, and Michael Brintnall. 2007. "Data Snapshot: The Proportion of Women in the Political Science Profession.” http://www.apsanet.org/imgtest/ Website\%2obrief\%20on\%20women\%20in\%20PS\%20v2\%201\%202007.pdf.

\section{APPENDIX: \\ Comparison of Respondents to the Discipline}

Because of the small number of respondents in our survey who reported racial identifications other than white, we used gender as a baseline for comparison. In the APSA's annual membership data, fields broke down by gender as reported in Table 2a. As we might expect, women tend to be more prevalent in the fields of comparative politics and public policy, and less present in international relations, though the discrepancies are not great (comparative coming in at $32.7 \%$ female and international relations at $28.1 \%$ female). No respondents in APSA's data were coded as transgender.

In the LGBT survey, respondents fell into the fields by gender as reported in Table $2 \mathrm{~b}$. The first discrepancy we note is in the overall gender percentages: survey respondents were nearly $40 \%$ female, whereas APSA data indicated just under $30 \%$ female. The distribution of respondents across fields differed substantially as well. While American was the largest field in both, the field comprised $24.1 \%$ of APSA's regular members as compared to $37.4 \%$ of the survey respondents. The fields of comparative politics and methodology were both substantially underrepresented in the survey, while international relations and public law were somewhat less overrepresented. Survey respondents did not separately identify themselves as public policy scholars, so some of the public administration survey respondents could correspond with APSA members in public policy.

Comparing the cells more specifically, we note that, while the survey respondents overall were more likely to be female than the APSA members, the difference was particularly striking among survey respondents who identified themselves as comparativists.
We also compared 2007 membership data provided to us by APSA to the survey respondents with respect to rank and gender, looking at the basic categories of assistant, associate, and full professor. See table 3a.

As one might expect, women are more prevalent at lower ranks, and there is a significant drop-off between associate and full professor. Table $3 \mathrm{~b}$ reports the same data for survey respondents.

The breakdown by rank is relatively comparable, with the survey respondents appearing to be slightly more junior than the APSA members. A higher percentage of the survey respondents reporting academic rank were also female than the APSA members, with assistants and fulls showing an approximately 4 percentage point discrepancy in favor of females among the survey respondents. Women comprised $30.3 \%$ of associate professors among the APSA members and $36.8 \%$ of associate professors among the survey respondents. 


\section{APPENDIX (continued)}

In thinking about the extent to which the survey reflects attitudes in the discipline, we note that a substantial number of respondents in the survey did not indicate academic rank and 117 additional respon- dents identified themselves as instructors, visitors, adjuncts, or lecturers.

In terms of age, the percentage of LGBT respondents tended to go down over time, with the exception of the 40-49-year-old respondents. The survey design and our concerns about non-response biases among the respondents prevent us from drawing any firm conclusions about this pattern or the possible causes of it, but it does hint at a possible correspondence with findings concerning other subordinated groups that members of these groups are more prevalent in the profession at earlier career stages. Seetable 5a.

Table $2 a$

APSA Membership Fields by Gender

\begin{tabular}{|c|c|c|c|}
\hline FELD & $\begin{array}{c}\text { FEMALE } \\
\text { (\% FEMALE IN FIELD) }\end{array}$ & $\begin{array}{c}\text { MALE } \\
\text { (\% MALE IN FIELD) }\end{array}$ & $\begin{array}{c}\text { TOTAL } \\
\text { (\% OF TOTAL FOR FIELD) }\end{array}$ \\
\hline American Politics & 535 (26.6\%) & 1,479 (73.4\%) & $2,014(24.1 \%)$ \\
\hline Comparative Politics & 577 (32.7\%) & 1,187 (67.3\%) & 1,764 (21.1\%) \\
\hline nternational Relations & 409 (28.1\%) & 1,045 (71.9\%) & 1,454 (17.4\%) \\
\hline Methodology & 138 (21.9\%) & 491 (78.1\%) & $629(7.5 \%)$ \\
\hline Political Theory & 260 (28.9\%) & $640(71.1 \%)$ & 900 (10.8\%) \\
\hline Public Law & $154(30.0 \%)$ & 359 (70.0\%) & $513(6.1 \%)$ \\
\hline Public Administration & 77 (29.1\%) & 188 (70.9\%) & 265 (3.2\%) \\
\hline blic Policy & $262(31.7 \%)$ & $565(68.3 \%)$ & 827 (9.9\%) \\
\hline & $2412(28.8 \%)$ & 5954 (71.2\%) & $8366(100 \%)$ \\
\hline
\end{tabular}

Note: See Sedowski and Brintnall (2007)

Table $2 b$

Survey Respondents' Fields by Gender

\begin{tabular}{lcccc} 
FIELD & TRANSGENDER & FEMALE & MALE & TOTAL \\
\hline American Politics & $2(0.2 \%)$ & $290(36.0 \%)$ & $515(63.8 \%)$ & $807(37.4 \%)$ \\
\hline Comparative Politics & $0(0 \%)$ & $152(50.2 \%)$ & $151(49.8 \%)$ & $303(14.0 \%)$ \\
\hline International Relations & $1(.2 \%)$ & $156(35.5 \%)$ & $282(64.2 \%)$ & $439(20.4 \%)$ \\
\hline Methodology & $0(0 \%)$ & $4(40 \%)$ & $6(60 \%)$ & $10(.5 \%)$ \\
\hline Political Theory & $0(0 \%)$ & $86(37.9 \%)$ & $141(62.1 \%)$ & $227(10.5 \%)$ \\
\hline Public Law & $0(0 \%)$ & $47(40.2 \%)$ & $70(59.8 \%)$ & $117(5.4 \%)$ \\
\hline Public Administration & $0(0 \%)$ & $82(39.2 \%)$ & $127(60.8 \%)$ & $209(9.7 \%)$ \\
\hline Other & $0(0 \%)$ & $27(60 \%)$ & $18(40 \%)$ & $45(2.1 \%)$ \\
\hline Total & $\mathbf{3 ( 0 . 1 \% )}$ & $\mathbf{8 4 4 ( 3 9 . 1 \% )}$ & $\mathbf{1 3 1 0 ~ ( 6 0 . 7 \% )}$ & $\mathbf{2 1 5 7 ~ ( 1 0 0 \% )}$
\end{tabular}

Table $3 a$

Breakdown of Political Science Faculty by Rank and Sex

\begin{tabular}{lcccc} 
& ASSISTANT & ASSOCIATE & FULL & TOTAL \\
\hline Female $(\% \mathrm{~F})$ & $1,119(36.9 \%)$ & $666(30.3 \%)$ & $628(20.0 \%)$ & $2,413(28.8 \%)$ \\
\hline Male $(\% \mathrm{M})$ & $1,910(63.1 \%)$ & $1,529(69.7 \%)$ & $2,515(80.0 \%)$ & $5,954(71.2 \%)$ \\
\hline Total (\% rank) & $\mathbf{3 , 0 2 9 ( \mathbf { 3 6 . 2 } \% )}$ & $\mathbf{2 , 1 9 5 ( \mathbf { 2 6 . 2 } \% )}$ & $\mathbf{3 , 1 4 3 ( 3 7 . 6 \% )}$ & $\mathbf{8 , 3 6 7 ( \mathbf { 1 0 0 } \% )}$
\end{tabular}

Note: Data provided by APSA. 
Table $3 b$

Survey Respondents by Rank and Sex

\begin{tabular}{lcccc} 
& ASSISTANT & ASSOCIATE & FULL & TOTAL \\
\hline Transgender (\% TG) & $2(0.4 \%)$ & $2(0.6 \%)$ & $0(0 \%)$ & $4(0.3 \%)$ \\
\hline Female (\% F) & $206(41.0 \%)$ & $130(36.8 \%)$ & $101(23.9 \%)$ & $437(34.2 \%)$ \\
\hline Male (\% M) & $295(58.6 \%)$ & $221(62.6 \%)$ & $321(76.1 \%)$ & $837(65.5 \%)$ \\
\hline Total (\% rank) & $\mathbf{5 0 3 ( 3 9 . 4 \% )}$ & $\mathbf{3 5 3 ( 2 7 . 6 \% )}$ & $\mathbf{4 2 2 ( 3 3 . 0 \% )}$ & $\mathbf{1 , 2 7 8 ( \mathbf { 1 0 0 } \% )}$ \\
\hline
\end{tabular}

Note: For this table, we have included the one person who self-reported as a distinguished professor in the full-professor category.

Table $5 a$

Age and Orientation/Identity

\begin{tabular}{lccccccr} 
AGE & BISEXUAL & GAY & LESBIAN & TRANS & \%LGBT & HETEROSEXUAL & TOTAL \\
\hline $20-29$ & $23(6 \%)$ & $33(9 \%)$ & $11(3 \%)$ & $0(0 \%)$ & $\mathbf{1 7 . 6}$ & $313(82 \%)$ & 380 \\
\hline $30-39$ & $32(4 \%)$ & $48(6 \%)$ & $31(4 \%)$ & $2(.3 \%)$ & $\mathbf{1 5 . 1}$ & $635(85 \%)$ & 748 \\
\hline $40-49$ & $14(3 \%)$ & $38(8 \%)$ & $22(5 \%)$ & $2(.4 \%)$ & $\mathbf{1 6 . 7}$ & $380(83 \%)$ & 456 \\
\hline $50-59$ & $16(5 \%)$ & $16(5 \%)$ & $12(4 \%)$ & $2(.6 \%)$ & $\mathbf{1 4 . 6}$ & $270(85 \%)$ & 316 \\
\hline $60-69$ & $10(5 \%)$ & $6(3 \%)$ & $2(1 \%)$ & $0(0 \%)$ & $\mathbf{8 . 4}$ & $196(92 \%)$ & 214 \\
\hline $70-$ & $1(2 \%)$ & $0(0 \%)$ & $0(0 \%)$ & $0(0 \%)$ & $\mathbf{2 . 1}$ & $47(99 \%)$ & 48 \\
\hline Total & $\mathbf{9 6}$ & $\mathbf{1 4 1}$ & $\mathbf{7 8}$ & $\mathbf{6}$ & $\mathbf{1 4 . 9}$ & $\mathbf{1 , 8 4 1}$ & $\mathbf{2 , 1 6 2}$ \\
\hline
\end{tabular}

